\title{
Massive intra and extracranial benign meningioma metastasizing to the lung and spine: the problem of meningiomas classification and iatrogenic metastasizing
}

\author{
Henning Drews ${ }^{1}$, Clemar Correa ${ }^{2}$, Hector Navarro Cabrera ${ }^{3}$, Eberval Gadelha \\ Figueiredo ${ }^{4}$, Leonardo Christiaan Welling ${ }^{5}$, Manoel Jacobsen Teixeira ${ }^{6}$
}

Department of Clinical Pharmacology, University Hospital of Tuebingen, Germany and Division of Neurological Surgery, Hospital das Clínicas University of Sao Paulo, SP, Brazil.

\begin{abstract}
Meningioma is a common CNS tumor and metastasis in these tumours is a rare occurrence. Malignant meningiomas are more prone to metastase. However, there are frequent case reports of metastases in atypical (grade II) and even benign (grade I), which demonstrates the somehow unsatisfying prognostic power of the current classification system. We describe an extraordinary case of a patient with a massive intra and extra-cranial, benign meningioma, metastasizing to both lung and spine. Following the report we discuss 1) some of the problems of classifying meningioma, 2) massive meningiomas and 3) the possibility of intra-operative iatrogenic metastasizing. This case is unique due to its combination of different sites of metastases, massiveness, invasive growth and benign histology. Thus it ranks among those rare but not uncommon complicated courses in meningioma which is otherwise a common benign tumor. Unfortunately the existing classification-criteria do not have sufficient power to predict such complicated courses.
\end{abstract}

\section{KEYWORDS}

Meningioma, neoplasm metastasis, brain neoplasms.

\section{RESUMO}

Meningioma benigno intra e extracraniano com metástase para pulmão e coluna: o problema da classificação e disseminação iatrogênica

Meningioma é um tumor comum que raramente metastatiza, principalmente em casos de meningiomas malignos. Contudo, há casos frequentes de metástases em casos de tumores benignos ou atípicos, o que denota evidente falha no sistema atual de classificação desses tumores. Os autores descrevem o caso de um paciente com extenso meningioma benigno intra e extracraniano que metastizou para pulmões e coluna e adicionalmente discutem questões relativas a classificação e mecanismos de disseminação hematogênica.

\section{PALAVRAS-CHAVE}

Meningioma, metástase neoplásica, neoplasias encefálicas.

1 Medical student of Department of Clinical Pharmacology, University Hospital of Tuebingen, Germany.

2 Head of Neuro-oncology team Division of Neurosurgery of Hospital das Clínicas, University of Sao Paulo (USP), Brazil.

3 Director, Division of Functional Neurosurgery of Hospital das Clínicas, USP, Brazil.

4 Head of Neurovascular Group and Supervisor of Division of Neurosurgery of Hospital das Clínicas, USP, Brazil.

5 Neurosurgeon, Post-Graduation Program, USP, Brazil.

6 Chairman, Division of Neurosurgery Hospital das Clínicas, USP, Brazil. 


\section{Introduction}

Meningioma is a rather common tumor, accounting for about $13 \%-26 \%$ of all central nervous system (CNS) neoplasms. ${ }^{1}$ It might be associated with neurofibromatosis type $2^{2}$ or previous exposition to radiation or trauma. ${ }^{3,4}$ Metastasis in meningioma is a rare entity. When present, most of the cases occur in malign meningioma. However, there are frequent case reports of metastases in atypical (grade II) and even benign (grade I), ${ }^{1,5}$ which demonstrates the somehow unsatisfying prognostic power of the current classification system. Metastasizing pathways are either hematogenous, lymphatic or via cerebrospinal fluid (CSF). ${ }^{6}$ The former is the most common, leading to lung metastasis predominantly. Vertebral metastasis is rarely reported. Iatrogenic metastasizing during surgery is a known phenomenon in meningioma surgery and sometimes associated with spinal drop metastasis. ${ }^{7}$

We describe an extraordinary case of a patient with a massive intra and extracranial, benign meningioma, metastasizing to both lung and spine. Although two rare cases of multiple metastases in meningioma have been recently reported ${ }^{8,9}$ this case seems to be unique due to the combination of different sites of metastasis, massiveness, invasive growth and benign histology. Following the case-report we discuss 1) some of the problems of classifying meningioma, 2) massive meningioma and 3) the possibility of intrasurgical iatrogenic metastasizing.

\section{Case report}

Patient presented with parietal and occipital tumorous masses of approximately $10 \mathrm{~cm}$ and $7 \mathrm{~cm}$ in maximum diameter respectively (Figure 1 ). The symptoms included hemiparesis and cervicalgia which have been four months long. In the previous four years, he had undergone a surgical resection of a symptomless, giant grade II meningioma (20 cm in diameter) of the rear part of the vertex (with a reported growth period of eight months). Thus, a recurrence of this meningioma was suspected. Physical examination confirmed the hemiparesis and cervicalgia but did not reveal further symptoms. No familiar history of meningioma, neurofibromatosis type II or preceding radiation therapy were present.

Radiological evaluation showed parietal and occipital masses of 10 and $7 \mathrm{~cm}$ respectively (Figures $2 \mathrm{~A}$ and $\mathrm{B})$ and a destructive lesion of the first thoracic vertebral body compressing the spinal cord (Figure 3). Patency of the sagital sinus was evidenced on MRI. Angiogram was not performed. Moreover, $5.0 \mathrm{~cm}$ pulmonary mass was detected in the right inferior lobe suggesting a metastatic lesion. Chest surgeons decide to carry out a transbronchial biopsy that was inconclusive for metastasis. Subsequently, an anterior spinal decompression, with chests surgeons' support, was performed. Lesion was interpreted as meningioma (Figure 4).

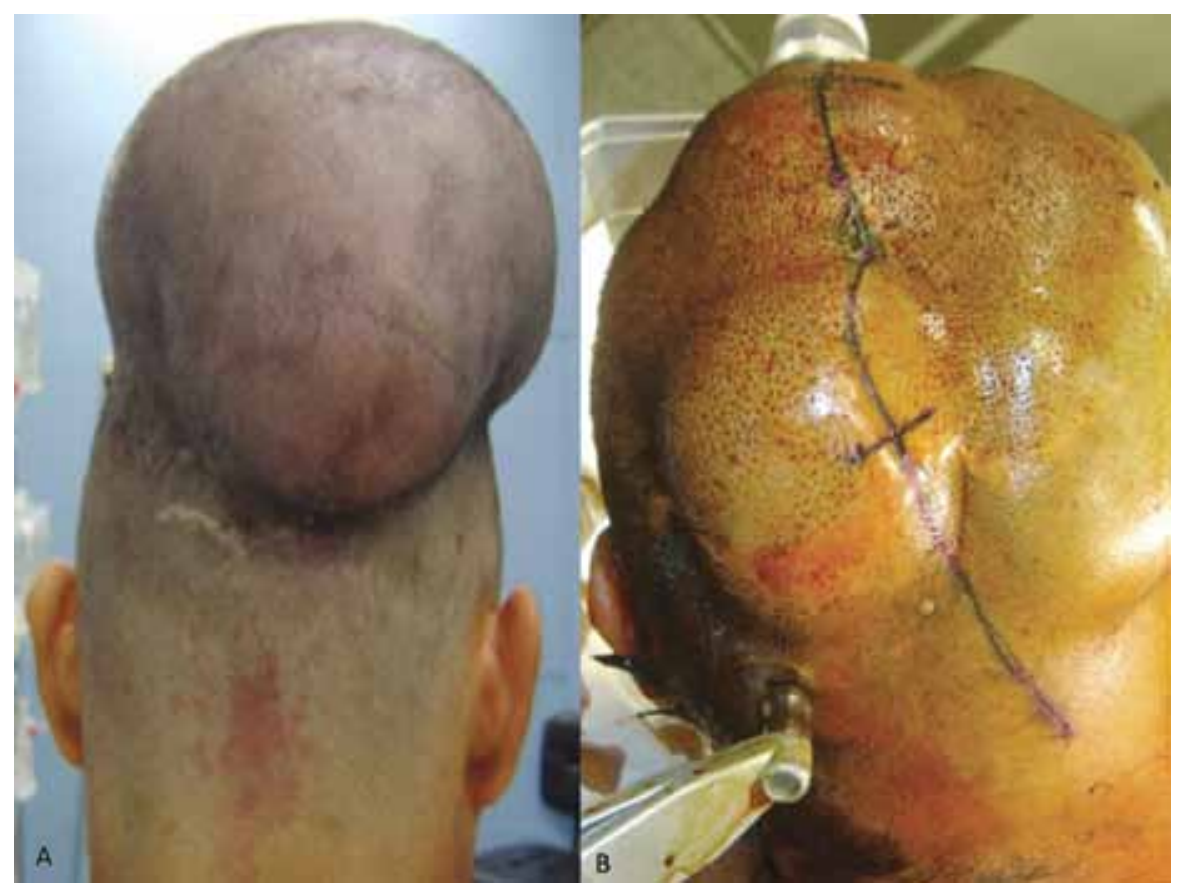

Figure 1 - Preoperative images depicting two parietal and occipital masses of approximately $10 \mathrm{~cm}$ and $7 \mathrm{~cm}$ diameter respectively. 

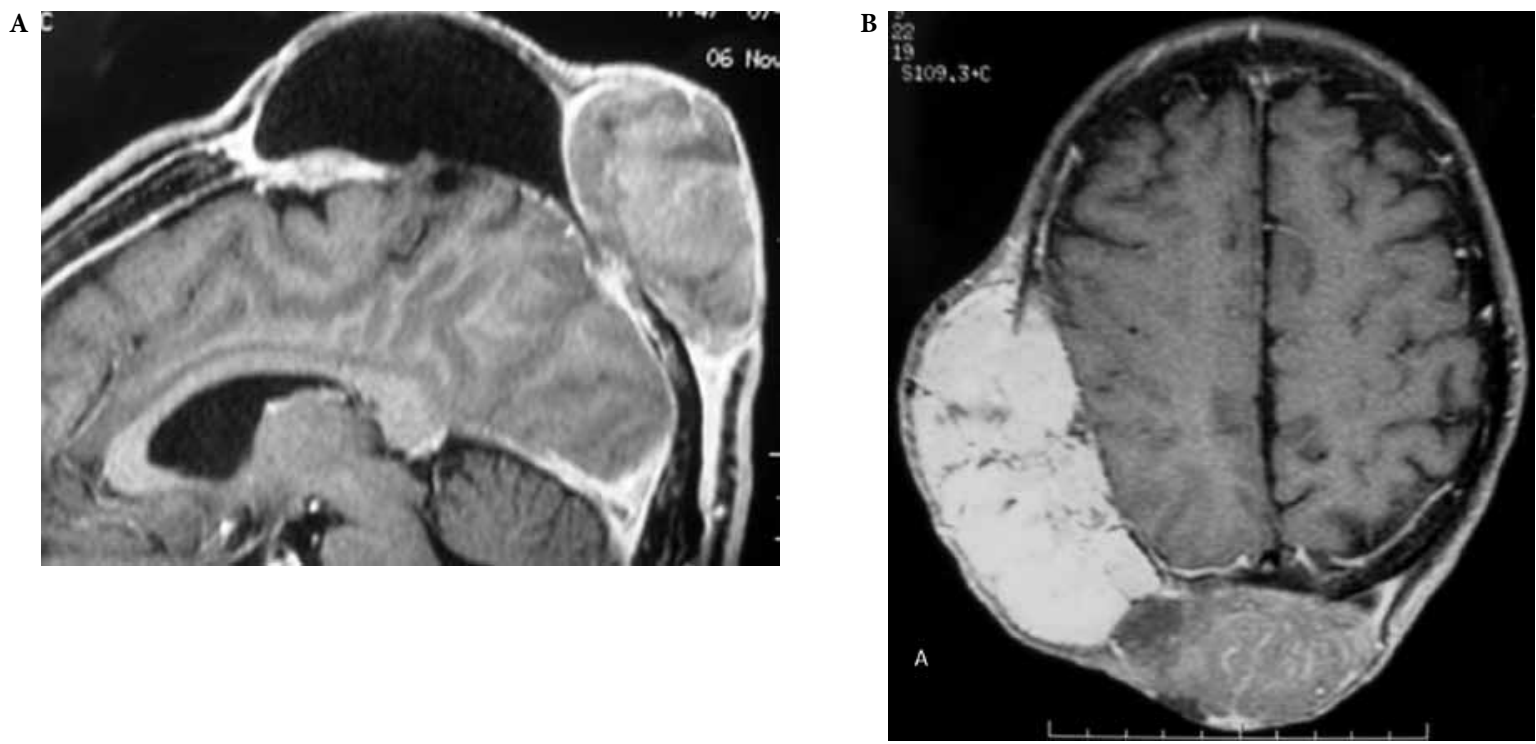

Figure 2 - (A) Sagital view of MRI image reveals a solid-cistic lesions with apparent invasion of dural sinuses suggesting meningioma. (B) Axial view after gadolinium injection.

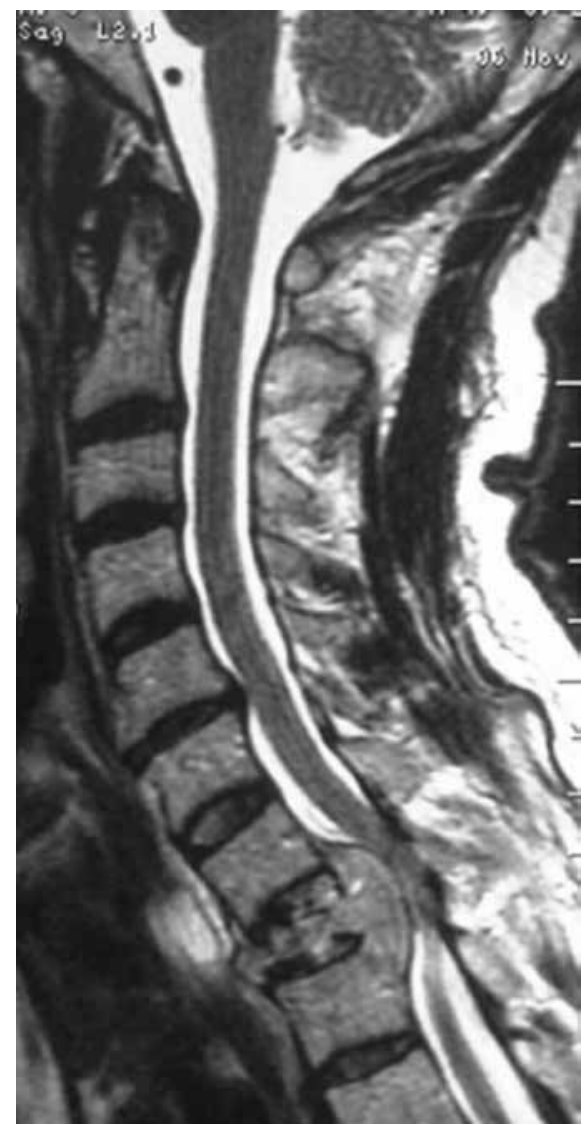

Figure 3 - MRI - Sagital view displays extradural mass compressing the spinal cord and compromising the $T 1$ vertebral body.

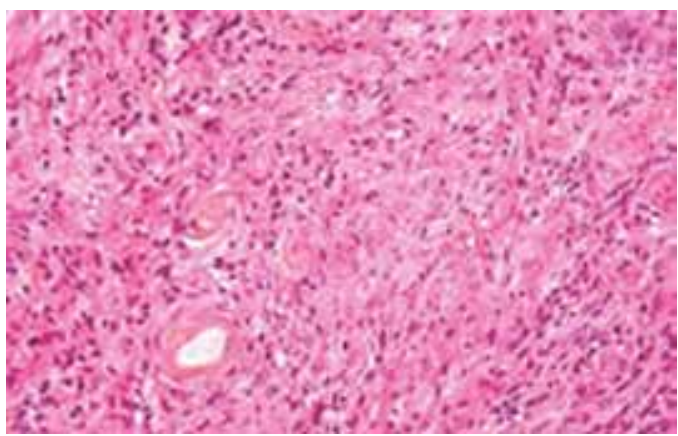

Figure 4 - Histopathological view. Sample from spine lesion suggestive of meningioma.

Next the cranial masses were operated on. A straight sagital skin incision was performed over the fronto-parieto-occipital regions. Scalp was easily dissected away from the masses, due to favorable surgical planes. Osteotomies were performed around the lesions and bony flaps were removed. Superior sagital sinus was individualized in its proximal and distal segments. Tumors were removed piecemeal and despite of significant hemorrhage, controlled by bipolar coagulation and hemostatics application, a complete resection was possible, with some doubts concerning the medium segment of the superior sagital sinus. The cranial mass was pathologically categorized as a grade I meningioma (Figure 5). Pulmonary lesion was left untreated. 


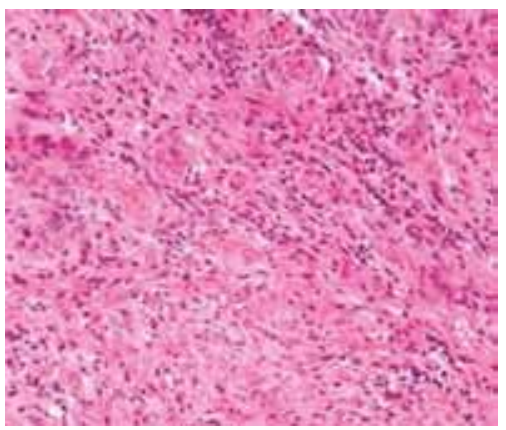

Figure 5 - Histopathological view. Sample from cranial lesion suggestive of meningioma.

\section{Discussion}

The present case represents a recurrent histologically benign massive meningioma with invasive osteoclastic growth and multiple metastases to the lungs and vertebrae, which makes it a case never described before in the literature known to the authors.

Eighty to ninety per cent of meningiomas are benign (grade I) and amenable to surgical treatment. The remaining which consist of atypical and anaplastic meningiomas tend to take an aggressive course, with metastatic activity $(0.1 \%$ overall, $5 \%$ in atypical, $30 \%$ in malignant meningiomas) ${ }^{10-12}$ fast and invasive growth, and local recurrence (7\%-20\% in benign meningiomas, compared to $30 \%-40 \%$ and $50 \%-80 \%$ in atypical and malignant meningiomas, respectively). ${ }^{13}$ Usually - unlike the case presented - meningiomas tend to become more atypical along the course of recurrences. ${ }^{14}$

\section{1) The classification problem}

An aggressive course, however, seems to be only approximately predictable by the $\mathrm{WHO}$-grading-system as there are initially benign meningioma with fast fatal courses. The proportion of those cases stated in literature, rises as high as $60 \%$ of all metastatic meningioma. ${ }^{15,16}$ Therefore, some peculiarities concerning the classification of meningioma and especially those with an aggressive course should be noticed.

The WHO grading system is based on histopathological findings. It distinguishes 15 histological subtypes, all of which may take a fatal curse. ${ }^{17}$ Atypical meningiomas show an augmented mitotic activity (> 4 mitosis per 10 high-power fields), with at least three of the following features: increased cellularity, small cells with high nucleus-to-cytoplasm ratio, prominent nucleoli, uninterrupted pattern sheet-like growth and foci of necrosis. ${ }^{18}$ Anaplastic meningiomas display frank malignancy. The WHO classification was revisited in 2000 which has further improved its prognostic capacity. ${ }^{19}$ However, this on-going evolution of the classification criteria has a direct impact on research, especially when dealing with rare cases such as recurrent multimetastic benign meningioma. The cases being taken into account spread over an extensive period of time comprising various classification systems which bears the danger of terminological nebulosity.

Moreover $\mathrm{p}-53$ expression, ${ }^{19}$ 1p/19q state, MIB-1 labeling index, BRDU and PCNA staining possibly provide useful information to determine the biological properties of meningiomas. ${ }^{9,20-23} \mathrm{~A}$ simple but promising approach - at least for the early detection of metastasis - could be CSF sampling for tumor cells. Chamberlain and Glantz ${ }^{5}$ found tumor cells in the CSF of all eight patients with metastatic meningioma, in a total population of 200 patients with meningioma.

Thus the continuous progress in the classification of meningioma nurtures the expectation for successive improvement. Yet, a certain lack of a classification system with powerful prognostic criteria is still to be acknowledged. ${ }^{7,19,24}$ Besides, some authors state a more practical problem: a certain incautious attitude might prevail amongst pathologists when dealing with "only meningioma" leading to insufficient analysis and in consequence to undergrading. ${ }^{2,6}$ This means that some of the reports of benign metastatic meningioma should be doubted.

\section{2) Massive meningioma}

Massive meningiomas are rare with decreasing incidence as health care improves and health conscience increases. ${ }^{25}$ In a literature review Nadkarni et al. ${ }^{25}$ report massive meningiomas weighting from 375 to 2,600 g. Massive meningiomas are usually of benign histology and unlike the case reported here rarely metastasize. However, as metastases in meningioma are often asymptomatic and seldom the cause of death ${ }^{24}$ this thesis could be questioned, especially as most of the patients with massive meningioma reported in literature never underwent screening for metastasis with modern techniques. On the other hand, a possible explanation could be a dissociation of growth and other features of malignancy as metastatic activity as proposed by Delgado-López et al. ${ }^{15}$ This could also account for the metastatic activity of benign meningioma. However, this point of view is broadly disagreed. Especially Drummond explicitly connects growth and namely invasive growth with the ability to metastasize.

The most common causes of death in massive meningioma are intraoperative exsanguinations and infection of skin ulceration resulting from mainly extra- 
cranial growth of many massive meningiomas. ${ }^{25}$ Hence massive meningiomas grow osteolyticly which occurs in $10 \%-17 \% .{ }^{26}$ Both Nadkarni et al..$^{25}$ and Yamada et al. ${ }^{26}$ recommend considering bone-invasive meningiomas as malignant, the former by comparing meningioma to other intracranial tumors and by presenting a case in which the extracranial portion on a massive meningioma has a higher MIB-1 labelling index than the intracranial portion.

\section{3) Iatrogenic metastasizing}

In metastatic meningioma main sites of metastasis are lung and pleura, accounting for about $60 \%$ of the metastatic cases. ${ }^{27}$ Other reported locations are liver, ${ }^{28}$ cervical lymph nodes ${ }^{29,30}$ kidneys, ${ }^{31}$ adrenal glands, bones including vertebrae, ${ }^{8}$ and skin. ${ }^{7,32}$ Metastases decrease median survival to less than 2 years. ${ }^{12}$ About half of the patients with metastatic meningioma develop multiple metastases. ${ }^{30}$ Vertebral metastases account for about 7\%. In a 2006 literature review Delgado-López et al. ${ }^{15}$ found about a dozen cases. As described above, metastases mainly occur in malignant and atypical meningioma nonetheless there are frequent case reports of metastases in benign meningioma. ${ }^{31}$

Metastasizing pathways are hematogenous, lymphatic and via CSF. Venous spread is supposed to be the most common as in $75 \%$ of all cases of sinus invasion or previous surgery. ${ }^{33}$ In case of metastasis affecting the spine, hematogenous metastasizing via Batson's plexus is proposed as well as spinal drop metastasis via the CSF. $5,7,8$ The latter is argued to be sometimes associated with intra-operative iatrogenic spread of tumor cells. The occurrence and relevance of iatrogenic metastasizing in meningioma surgery is still subject to discussion. On the one hand, there are reports of cutaneous meningiomas being linked to the surgery of a previous meningioma. ${ }^{32,34}$ Moreover the vast majority of metastatic meningioma has undergone surgery prior to the occurrence of metastases. On the other hand there are reports of metastatic meningioma without surgery $y^{35}$ and almost every meningioma undergoes surgery whereas only a small proportion develops metastatic activity. ${ }^{7}$

In the case presented measures of reducing the danger of intra-operative metastasis (changing of instruments, gloves and draping) were undertaken. However taking into account the massive haemorrhage, we cannot exclude the possibility of surgery having contributed to the metastatic course.

We thus conclude, as one cannot exclude the possibility of iatrogenic metastasizing in meningioma and the metastatic potential can hardly be evaluated preoperatively, which is due to the described classification problems, all intra-operative measures should be performed to counteract tumor cell spread. Moreover, further measures such as a full body screening for metastasis or CSF sampling should be considered especially in recurrent meningioma and when sinus invasion has occurred. ${ }^{5,7,8}$ Preventive radiation therapy may also help. ${ }^{34}$ In addition, further research on iatrogenic intra-operative metastasizing in meningioma is needed.

This case is unique due to its combination of different sites of metastases, massiveness, invasive growth and benign histology. Thus it ranks among those rare but not uncommon complicated courses in meningioma which is otherwise a common benign tumor. Unfortunately the existing classification-criteria do not have sufficient power to predict such complicated courses. Various parameters are currently studied to improve the situation. One simple and promising procedure could be CSF-sampling. Intra-operative iatrogenic metastasis is likely to occur in at least some cases. Facing the lack of prognostic criteria and possible iatrogenic tumor dissemination, strict intra-operative precautions possibly in combination with postoperative radiation should be considered.

\section{References}

1. Asioli S, Senetta R, Maldi E, D'Ambrosio E, Satolli MA, Bussolati G, et al. "Benign" metastatic meningioma: clinico-pathological analysis of one case metastasising to the lung and overview on the concepts of either primitive or metastatic meningiomas of the lung. Virchows Arch. 2007;450(5):591-4.

2. Perry A. Unmasking the secrets of meningioma: a slow but rewarding journey. Surg Neurol. 2004;61(2):171-3.

3. Gunkel AR, Kanonier G, Zelger B, Judmaier W. [Isolated extracranial meningioma of the facial soft tissues]. Laryngorhinootologie. 1997;76(1):50-2.

4. Manelfe C, Lasjaunias P, Ruscalleda J. Preoperative embolization of intracranial meningiomas. AJNR Am J Neuroradiol. 1986;7(5):963-72.

5. Chamberlain MC, Glantz MJ. Cerebrospinal fluiddisseminated meningioma. Cancer. 2005;103(7):1427-30.

6. Lee GC, Choi SW, Kim SH, Kwon HJ. Multiple extracranial metastases of atypical meningiomas. J Korean Neurosurg Soc. 2009;45(2):107-11.

7. Erkutlu I, Buyukhatipoglu H, Alptekin M, Berkyurek E, Tutar E, Gok A. Spinal drop metastases from a papillary meningioma: a case report and review of the literature: utility of CSF sampling. Med Oncol. 2009;26(2):242-6.

8. Samson Sujit Kumar G, Rajshekhar V. Deep sylvian meningioma: a case report and review of literature. Childs Nerv Syst. 2009;25(1):129-32.

9. Lee KS, Hoshino T, Rodriguez LA, Bederson J, Davis RL, Wilson CB. Bromodeoxyuridine labeling study of intracranial meningiomas: proliferative potential and recurrence. Acta Neuropathol. 1990;80(3):311-7.

10. Enam SA, Abdulrauf S, Mehta B, Malik GM, Mahmood A. Metastasis in meningioma. Acta Neurochir (Wien). 1996;138(10):1172-7. 
11. Gezen F, Kahraman S, Canakci Z, Bedük A. Review of 36 cases of spinal cord meningioma. Spine (Phila Pa 1976). 2000;25(6):727-31.

12. Strange RR, Tovi D, Nordenstam H. Meningioma with intracerebral, cerebellar and visceral metastases. J Neurosurg. 1964;21:1098-102.

13. Lamszus K. Meningioma pathology, genetics, and biology. J Neuropathol Exp Neurol. 2004;63(4):275-86.

14. LeMay DR, Bucci MN, Farhat SM. Malignant transformation of recurrent meningioma with pulmonary metastases. Surg Neurol. 1989;31(5):365-8.

15. Delgado-López PD, Martín-Velasco V, Castilla-Díez JM, Fernández-Arconada O, Corrales-García EM, GalachoHarnero A, et al. Metastatic meningioma to the eleventh dorsal vertebral body: total en bloc spondylectomy. Case report and review of the literature. Neurocirugia (Astur). 2006;17(3):240-9.

16. Tognetti F, Donati R, Bollini C. Metastatic spread of benign intracranial meningioma. J Neurosurg Sci. 1987;31(1):23-7.

17. Jääskeläinen J, Haltia M, Servo A. Atypical and anaplastic meningiomas: radiology, surgery, radiotherapy, and outcome. Surg Neurol. 1986;25(3):233-42.

18. Perry A, Scheithauer BW, Stafford SL, Lohse CM, Wollan PC. "Malignancy" in meningiomas: a clinicopathologic study of 116 patients, with grading implications. Cancer. 1999;85(9):2046-56.

19. Yang SY, Park CK, Park SH, Kim DG, Chung YS, Jung HW. Atypical and anaplastic meningiomas: prognostic implications of clinicopathological features. J Neurol Neurosurg Psychiatry. 2008;79(5):574-80.

20. Yang SY, Park CK, Park SH, Kim DG, Chung YS, Jung HW. Atypical and anaplastic meningiomas: prognostic implications of clinicopathological features. J Neurol Neurosurg Psychiatry. 2008;79(5):574-80.

21. Kleihues P, Louis DN, Scheithauer BW, Rorke LB, Reifenberger G, Burger PC, et al. The WHO classification of tumors of the nervous system. J Neuropathol Exp Neurol. 2002;61(3):215-25.

22. Nagasaka T, Gunji M, Hosokai N, Hayashi K, Fujino M, Ikeda $\mathrm{H}$, et al. Fluorescent in situ hybridization 1p/19q deletion/ imbalance analysis of low-gradeand atypical meningiomas. Neurol Med Chir (Tokyo). 2010;50(1):27-32.

23. Nakabayashi H, Sakaguchi M, Katsuyama J, Hakuba A. Proliferative potential of meningiomas evaluated by proliferating cell nuclear antigen expression. J Neurooncol. 1995;24(3):209-17.

24. Drummond KJ, Bittar RG, Fearnside MR. Metastatic atypical meningioma: case report and review of the literature. J Clin Neurosci. 2000;7(1):69-72.
25. Nadkarni T, Desai K, Goel A. Giant meningioma of the cranial vertex: case report. Neurol Med Chir (Tokyo). 2002;42(3):128-31.

26. Yamada SM, Yamada S, Takahashi H, Teramoto A Matsumoto K. Extracranially extended meningothelia meningiomas with a high MIB-1 index: a report of two cases. Neuropathology. 2004;24(1):66-71.

27. Baisden BL, Hamper UM, Ali SZ. Metastatic meningioma in fine-needle aspiration (FNA) of the lung: cytomorphologic finding. Diagn Cytopathol. 1999;20(5):291-4.

28. Ferguson JM, Flinn J. Intracranial meningioma with hepatic metastases and hypoglycaemia treated by selective hepatic arterial chemo-embolization. Australas Radiol. 1995;39(1):97-9.

29. Murrah CP, Ferguson ER, Jennelle RL, Guthrie BL, Holman WL. Resection of multiple pulmonary metastases from a recurrent intracranial meningioma. Ann Thorac Surg. 1996;61(6):1823-4.

30. Stoller JK, Kavuru M, Mehta AC, Weinstein CE, Estes ML, Gephardt GN. Intracranial meningioma metastatic to the lung. Cleve Clin J Med. 1987;54(6):521-7.

31. Pramesh CS, Saklani AP, Pantvaidya GH, Heroor AA, Naresh $\mathrm{KN}$, Sharma $\mathrm{S}$, et al. Benign metastasizing meningioma. Jpn J Clin Oncol. 2003;33(2):86-8.

32. Velnar T, Bunc $\mathrm{G}$. latrogenic metastasis of a benign meningioma to the periosteum at the site of previous craniotomy: a case report. Wien Klin Wochenschr. 2008;120(23-24):766-9.

33. Figueroa BE, Quint DJ, McKeever PE, Chandler WF. Extracranial metastatic meningioma. $\mathrm{Br} \mathrm{J}$ Radiol. 1999;72(857):513-6.

34. Lüdemann WO, Obler R, Tatagiba M, Samii M. Seeding of malignant meningioma along a surgical trajectory on the scalp. Case report and review of the literature. J Neurosurg. 2002;97(3):683-6.

35. Shuangshoti S, Hongsaprabhas C, Netsky MG. Metastasizing meningioma. Cancer. 1970;26(4):832-41.

Correspondence address

Eberval G. Figueiredo

Division of Neurological Surgery, Hospital das Clínicas,

University of Sao Paulo

Rua Dr. Enéas de Carvalho Aguiar, 255, Jardim Paulista

05403-000 - São Paulo, SP

E-mail: ebgadelha@yahoo.com 